\title{
Women of the Academy and the Sea
}

\author{
BY SUZANNE O'CONNELL AND MARY ANNE HOLMES
}

The oceans cover almost three-quarters of our planet, influencing food production, coastal erosion, sea-level rise, and natural disasters such as tsunamis and hurricanes. Those who study the oceans can be subdivided into four major fields: biological oceanography, chemical oceanography, physical oceanography, and geological oceanography (marine geology and geophysics). Although ing variety of associated themes and studies: wave mechanics, seafloor microbiology, and climate research, to name a few. The science is also continually evolving: paleoceanography and ocean remote sensing are just two of the new branches that have emerged in the last fifty years.

Women have played an active role in all areas of oceanography. Defining

\section{Women have played an active role in all areas of oceanography.}

\section{Defining the number of women oceanographers is not an easy task}

\section{because the discipline is so broad and the boundaries between}

\section{subdisciplines are not always distinct.}

oceanography also includes ocean engineering, public policy, and coastal oceanography, these disciplines were not considered in this study because they are "non-traditional" and participation therein is more difficult to track.

A look at schools and departments of oceanography reveals a rich and intrigu- the number of women oceanographers is not an easy task because the discipline is so broad and the boundaries between subdisciplines are not always distinct. For example, we (the authors of this article) study ocean sediments and have spent long months at sea on research vessels, yet neither of us con- sider "oceanography" our primary field of study. Our link to oceanography is through marine geology, and women marine geologists are included in this article. In contrast, we have not included marine biology as a discipline, but have included biological oceanography. Marine biology focuses on the biology and physiology of marine organisms whereas biological oceanography has a more interdisciplinary ecological approach and focuses more on the interactions of organisms and their environment.

There is no perfect way to look at women's participation in oceanography. What is clear, however, is that historically the experience of women in this field has been very different from that of

Suzanne O'Connell (soconnell@wesleyan. edu) is Associate Professor and Chair, Department of Earth and Environmental Sciences, Wesleyan University, Middletown, CT, USA. Mary Anne Holmes is Research Associate Professor, Geosciences Department, University of Nebraska-Lincoln, Lincoln, NE, USA. 
men. To assess how women have fared through the years, we have drawn on the publicly available data to examine the changes in women's role through time and to create a snapshot of current academic departments.

\section{WOMEN IN OCEANOGRAPHY THROUGH TIME}

We present data from two sources: the National Science Foundation (NSF) record of degrees granted (NSF, 2004) and women scientists' participation in Joint Oceanographic Institutions for Deep Earth Sampling (JOIDES) scientific ocean drilling research cruises (as given in cruise-related publications).

\section{National Science Foundation- Degrees Granted}

Since 1966, NSF has collected and published data about degrees granted at the bachelor's, master's, and Ph.D. level in different disciplines. The geosciences include Earth, atmospheric, and ocean sciences (EAOS). Degree data for these three disciplines can be viewed in one category or in the various subcategories. NSF data permit an assessment of broad trends in degrees granted to both total number and proportion of women in all EAOS fields (Figures 1 to 3 ). NSF data also permit comparison between women's participation in EAOS and women's participation in other fields (Figure 4).

Whether looking at total numbers (Figure 1) or proportion (Figure 2), it is clear that women's participation is increasing at all degrees levels within the EAOS category. The rate of increase

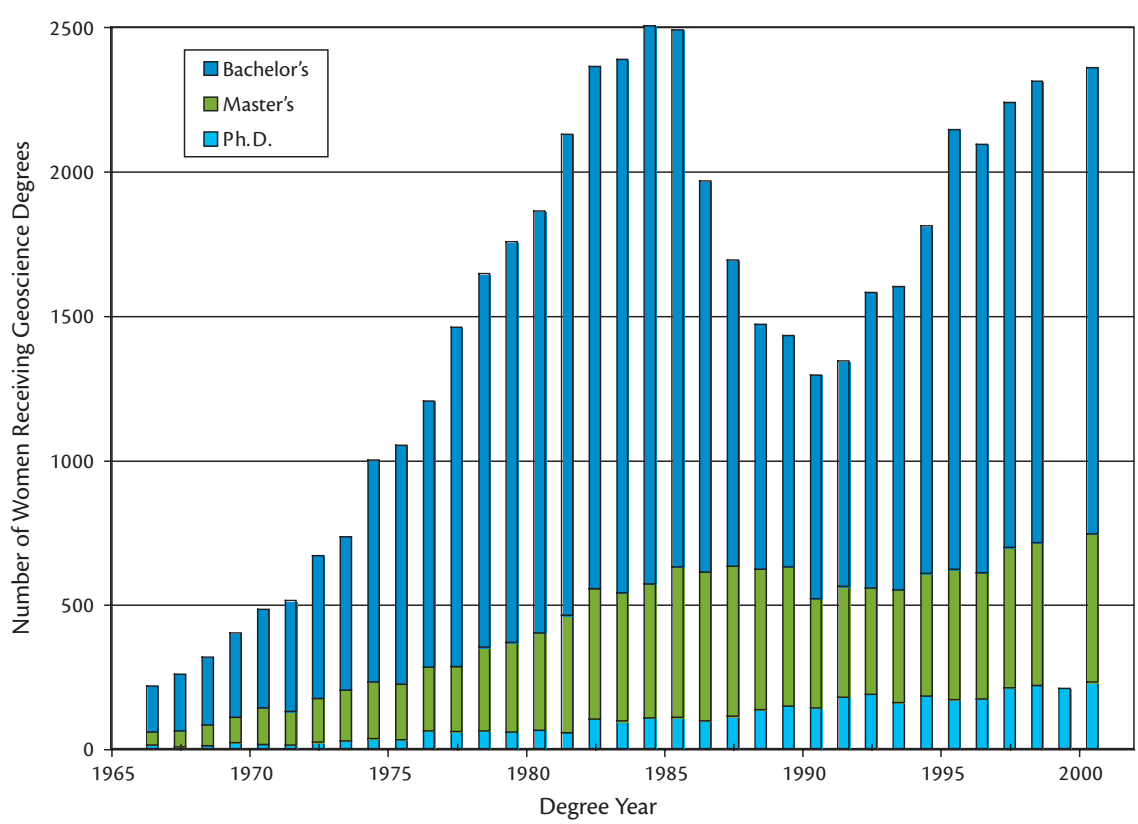

Figure 1. Number of women receiving bachelor's, master's and Ph.D. degrees in Earth, atmospheric, and ocean sciences, the three fields in the geosciences directorate at the National Science Foundation (NSF, 2004). Each value is a three-year running average centered at the middle year. Bachelor's and masters's degree data are not available for 1999 (NSF, 2004).

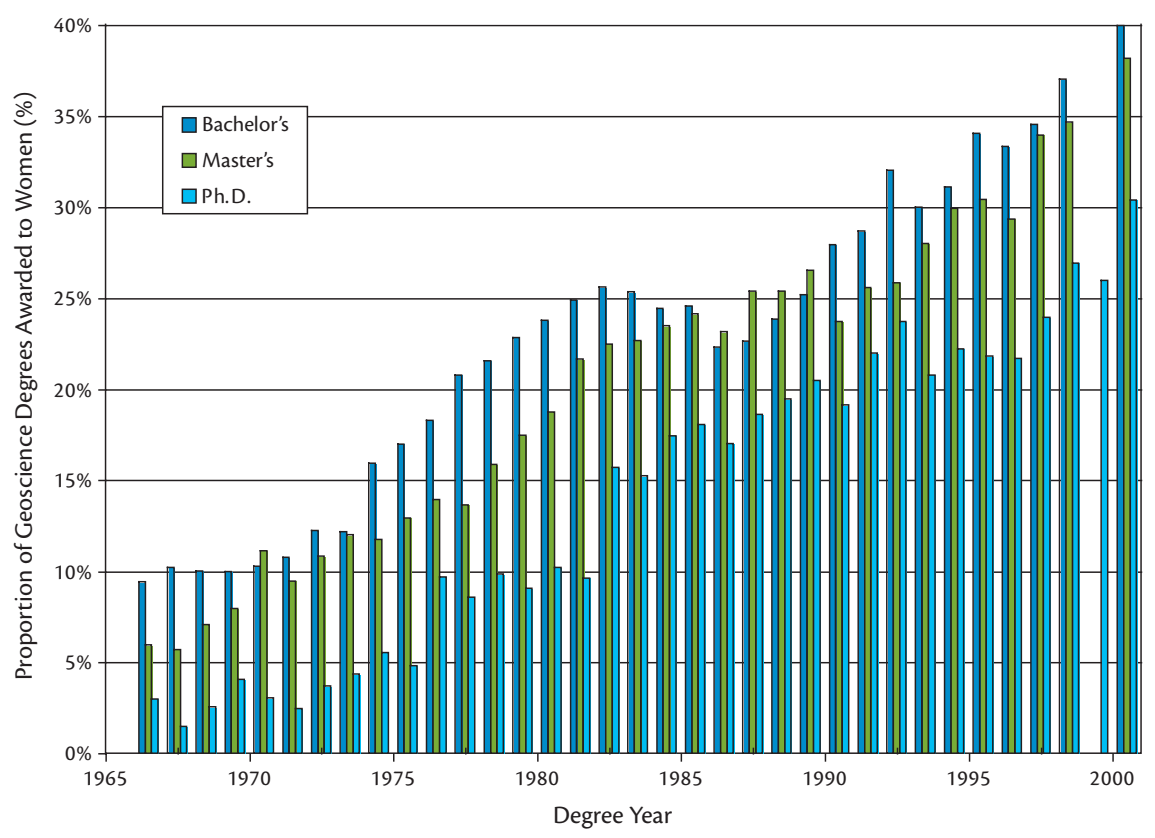

Figure 2. Proportion of women receiving bachelor's, master's and Ph.D. degrees in Earth, atmospheric, and ocean sciences. Each value is a three-year running average centered at the middle year. The proportions of women receiving geoscience degrees have risen faster than the absolute numbers (Figure 1) because fewer men are pursuing these fields. Bachelor's and master's degree data are not available for 1999 (NSF, 2004). 


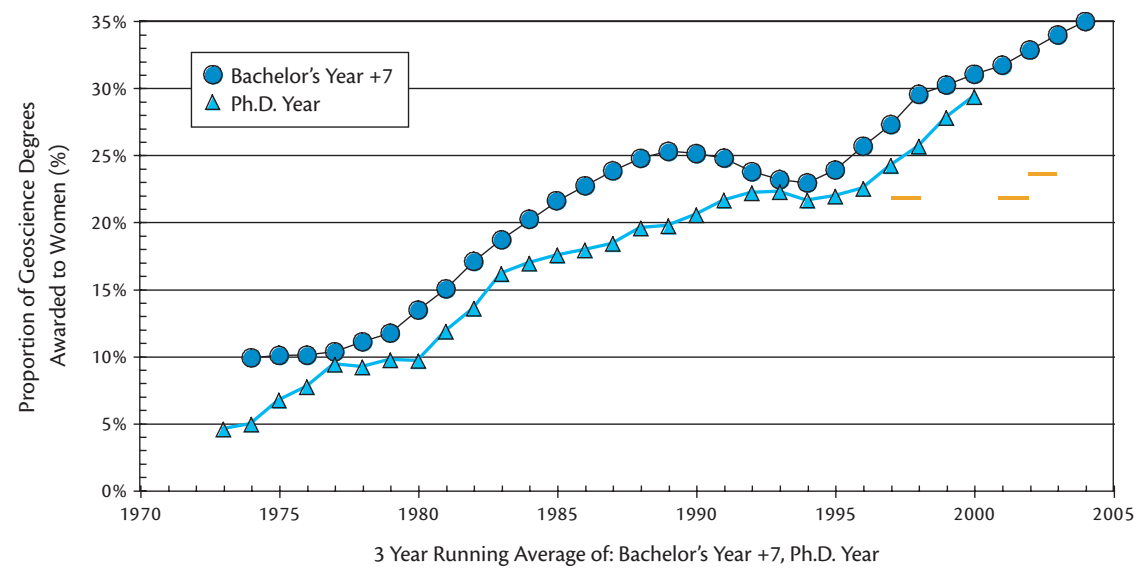

Figure 3. Proportion of women in degree cohorts for bachelor's degrees and Ph.D.s in geosciences using a three-year running average with degree year placed at Ph.D. year. The Ph.D. cohort used for comparison is set at seven degrees post-bachelor's degree (e.g., 1987 Ph.D. degree recipients are compared to 1980 bachelor's degree recipients), with data plotted at the Ph.D. year (NSF, 2004). Horizontal orange bars for 1997, 2001, and 2002 show the proportion of women in assistant professor, tenure-track geoscience positions at all degree granting institutions (bachelor's, master's and Ph.D.), based on data from the AGI directory (Claude, 1997, 2001, 2002). Scientists may become assistant professors immediately after receiving their Ph.D. or after several years as a post-doctoral researcher. Faculty are usually assistant professors for six or seven years.



Figure 4. Two degree cohorts for all STEM fields, calculated as in Figure 3. Women who receive a bachelor's degree in Earth sciences are more likely than any other science to continue on for a Ph.D. However, as a proportion of the field, fewer women major in the Earth sciences than any other science. The high retention rate may reflect women from other science fields receiving Ph.D.s in EAOS fields. None of the Ph.D. proportions distinguish between students earning their bachelor's degrees at a U.S. institution or abroad before entering a U.S. graduate program. Source: NSF (2004) and Holmes and O'Connell (2004). of the proportion of women receiving degrees is rising faster than the rate of increase of the number of women. The increase in the proportion of women earning degrees could be because the number of men pursing these degrees is increasing more slowly or not at all. This is clearly documented in the case of awarded oceanography Ph.D. degrees (Figure 5). At the current rate of increase, assuming the linear trend continues, women will receive more than 50 percent of EAOS bachelor's degrees before 2020 and more than 50 percent of EAOS Ph.D.s before 2030. Women already receive over 50 percent of biology undergraduate degrees (NSF, 2004).

Despite the increases in women's participation, fewer women than men enter the geosciences as undergraduates (Figure 2) and still fewer women than men continue on to graduate school to earn Ph.D.s. While it is true that in all fields of science that relatively few students continue on to earn a Ph.D., fewer women earn bachelor's degrees in science and more women discontinue their formal science education after completing their undergraduate degree. The result is that far fewer women than men prepare to enter graduate school and later academia. The data shows that 4,047 bachelor's degrees and 758 Ph.D.s were awarded in EAOS fields in 2000. Of these, 1,617 (40 percent) of the bachelor's degrees and 230 (30 percent) of the Ph.D.s were awarded to women (NSF, 2004).

To address the question of attrition, we looked at the proportion of women in degree cohorts. We assumed that someone who continued on to graduate school shortly after receiving a bachelor's degree would earn a Ph.D. seven years 
later. First, we examined this average for EAOS degrees awarded by year (Figure

3). There is only a slight decrease in the proportion of women receiving a Ph.D. relative to the proportion receiving a bachelor's degree. Over the last thirty years, there has never been more than a 5.5 percent difference between the proportion of men and women who have continued on to receive a Ph.D., when the data are lagged. In recent years, the proportional attrition gap is closing. However, a disturbing comparison is the proportion of women in tenure-track, assistant-professor positions (shown in orange for selected years, Figure 3 ). The gap between the proportion of Ph.D.s awarded to women and the proportion of women in tenure-track positions appears to be increasing, not decreasing. We will look at this further in the "snapshot" sections.

We also compared the proportion of degrees granted to women for all science, technology, engineering, and mathematics (STEM) fields for two bachelor's degree/Ph.D. degree cohorts separated by 25 years (Figure 4 ). Women recipients of bachelor's degrees have increased from an average of 16.8 percent in 1967 to 32.3 percent twenty-five years later (1992). Even though in all STEM fields women are less likely than men to pursue a Ph.D. (Figure 4) (NSF, 2004), the increase in women receiving Ph.D.s is even more impressive than their increases in bachelor's degrees. The STEM field increase in women receiving Ph.D.s is from 9.8 percent in 1974 to 27.4 percent in 1999.

Focusing on EAOS, the increase in the number of women students receiving bachelor's degrees and Ph.D.s over the course of twenty-five years is one of the

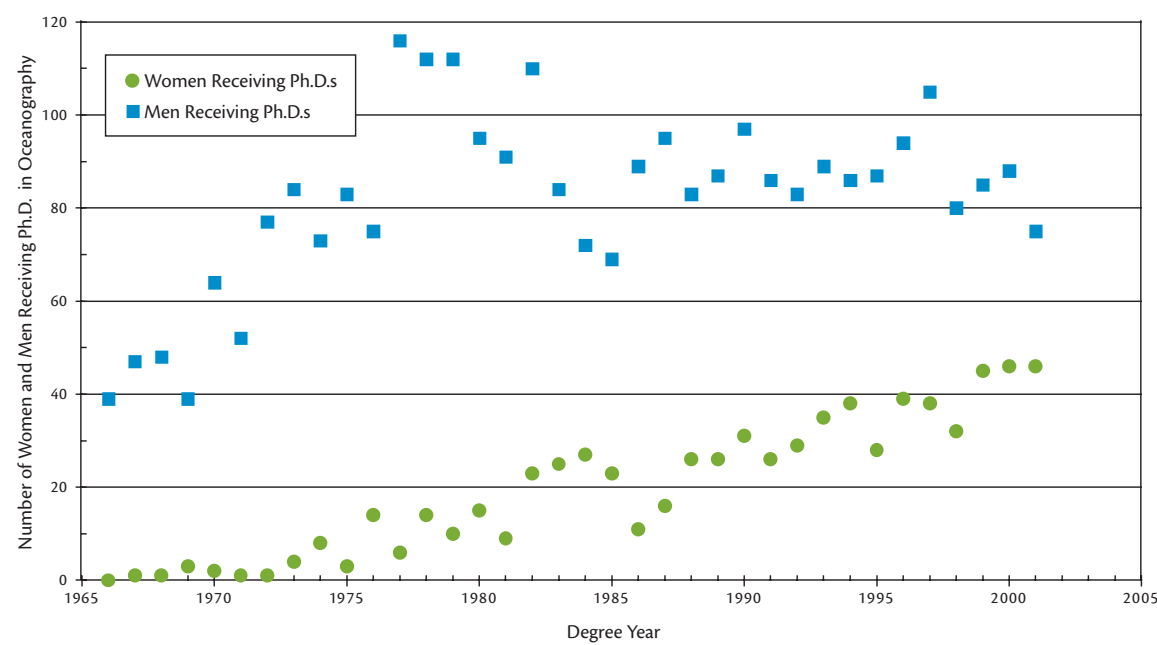

Figure 5. Number of women and men receiving Ph.D.s in oceanography between 1966 and 2001. Source: NSF (2004).

most improved. In the 1967 bachelor's degree and 1974 Ph.D. cohort, women comprised 9.9 percent and 4.9 percent of the degree recipients, respectively. For the 1992/1999 cohort, the percentages had increased to 30 percent and 27.8 percent, respectively.

In addition to actual retention, there are three other factors that may contribute to the high proportional rates of women continuing for the Ph.D. including: (1) decreasing numbers of men continuing for a Ph.D., (2) more women than men recruited from other fields to EAOS fields, and (3) increases in the number of foreign women in U.S. graduate programs. Oceanography is primarily a graduate discipline, therefore, it is likely that many oceanography Ph.D.s received their undergraduate degrees in non-EAOS fields such as physics, chemistry, mathematics, and biology. If women are being drawn into EAOS at a higher rate than men for graduate school, this could contribute to the high apparent retention rate of women in EAOS. The proportion of women receiving graduate oceanography degrees between 1966 and 2001 varies from 2 percent in the early 1970s to 38 percent in 2001 (NSF, 2004). This increase is due to both more women and fewer men entering the field (Figure 5).

The cohorts also do not take into account foreign students who enter the U.S. educational system at the graduate level, which would give the appearance of higher overall retention rates. If foreign women receive Ph.D.s at a higher rate than foreign men, this would increase the apparent retention rates for women. NSF provides data for Ph.D. recipients by nationality beginning in 1994 (NSF, 2003). Women who are U.S. citizens show the highest rate of increase, followed closely by non-citizen women (Figure 6). Non-citizen men remain roughly constant and the number of U.S. citizen men receiving Ph.D.s in EAOS field decreases. If the non-citizen men 

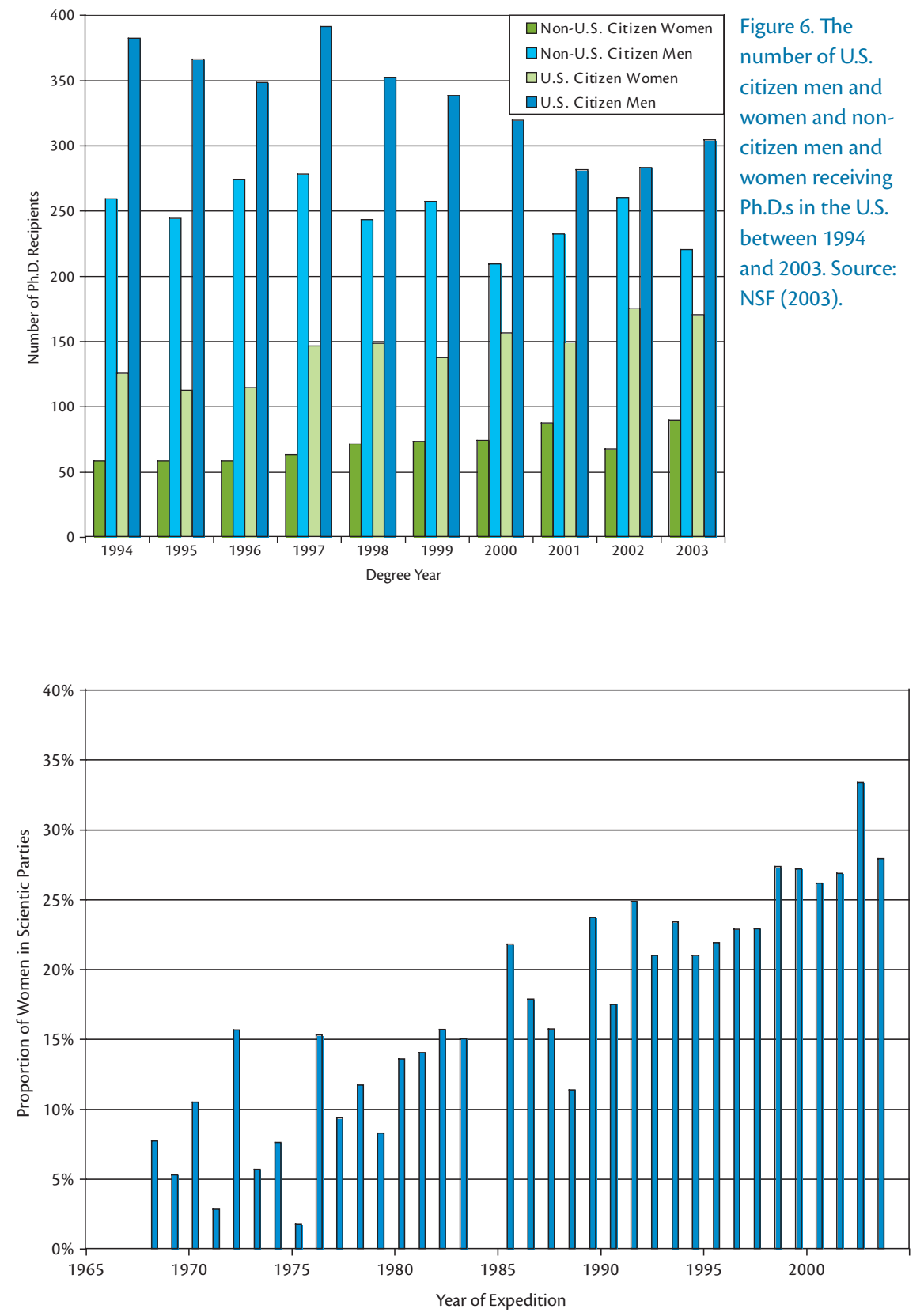

Figure 7. Proportion of women in DSDP (1968-1983) and ODP (1985-2003) scientific parties per year. Members of scientific parties are invited to participate and include graduate students, postdoctoral researchers and employed scientists. There are several differences between DSDP and ODP scientific parties. During DSDP scientific parties were generally twelve people, while during ODP they were generally about 24. Although scientists from outside the United States participated in early legs, the participation of non-U.S. scientists wasn't formalized until 1975 when Japan and four European countries joined the program. During ODP non-US participation expanded even further, although the number and composition of participating countries changed during the program. In the late 1960s and early 1970s, women comprised less than 10 percent of the scientific party. By the late 1990s and early 2000s, women comprised over 25 percent of the scientific party. Data from DSDP and ODP cruise lists are published at the beginning of report volumes. DSDP gender assignments were made on the basis of names, so there might be some error. ODP data from Tom Davies, Ocean Drilling Program, personal communication, 2005. and women did not receive their undergraduate degrees at U.S. institutions, then the Ph.D.-receiving non-citizen women contribute to the apparent higher retention rates of women.

\section{SCIENTIFIC OCEAN DRILLING}

\section{AND WORKFORCE STATISTICS}

Scientific ocean drilling began almost fifty years ago with the Mohole project (more information available at http:// www.nas.edu/history/mohole/). Since then, it has undergone several changes, both in the vessel used, the program organization, and the size and composition of the scientific party. The Deep Sea Drilling Project (DSDP) (1968-1983) originated as a U.S. program with the goal of learning about ocean history, especially the age of the ocean, by recovering samples of ocean sediments and the underlying oceanic crust throughout the oceans. Although it was begun as a U.S. program, scientists from other countries participated as shipboard scientists. International participation became formalized in 1975 when the governments of Japan and four European countries began financial contributions, assuring their scientists' involvement in the planning process and guaranteeing them scientific berths on the drilling vessel. This international structure, with the United States as the lead partner, continued in a successor program, the Ocean Drilling Program (ODP) (1985-2003). During ODP, the number of non-U.S. countries increased as did the size of the scientific party. The newest scientific ocean drilling program, the Integrated Ocean Drilling Program, has the U.S. and Japan as co-equal partners, and includes broad international participation as well. Drill- 
ing operations have only recently begun.

During the DSDP's 15 years of sea-going operations, 96 expeditions were completed in all of the world's oceans with the Glomar Challenger as the drilling vessel. Each expedition lasted about two months and was called a "leg." Scientists who participate in the leg form the scientific party. During DSDP, nearly 1,260 scientists sailed on the Glomar Challenger. Of these scientists, only 12.5 percent were women (Figure 7).

The successes of the DSDP were significant. The cores recovered allowed scientists to date the ocean floor with reasonable accuracy, proving beyond a doubt that oceanic crust aged away from mid-ocean ridge spreading centers; allowed the field of paleoceanography to develop and flourish; and increased our understanding of the processes at subduction zones.

When the Glomar Challenger became too old to meet the needs of the scientific community, a new program, the ODP began. ODP commissioned a larger ship, the JOIDES Resolution. This 471-footlong vessel allowed an increase in the size of scientific laboratories and in the number of scientists, meaning much more work could be done at sea. The new vessel was able to drill in high latitudes and address some of the major unsolved paleoclimate and paleoceanographic questions. The JOIDES Resolution also had better station-keeping and heavecompensating equipment. This equipment allowed drilling in rough weather and disturbed the cores less, making them more useful for detailed scientific analysis. Between 1985 and 2003, 109 ODP legs were completed. Almost 2,900 scientists participated, and 22.7 percent

of them were women (Figure 7).

Not shown in Figure 7 is the increase in women heading the drilling expeditions. The primary responsibility for ensuring the scientific results of each cruise rests with the two co-chief scientists.

These scientists are often the people who

\section{What is surprising is that even with the increase of women in both absolute numbers and proportions, the number of women remains so low at the entry level assistant professor rank.}

proposed the research and spent many years collecting the necessary background information to allow a leg to be drilled in a particular area to answer specific scientific questions. During DSDP, only four women sailed as co-chief scientists, beginning with Leg 25 in 1972, and ending with Leg 92 in 1983. During ODP, women were co-chief scientists on sixteen ODP legs, and on Legs 144 and 147 in particular, both co-chief scientists were women.

\section{WOMEN OCEANOGRAPHERS IN ACADEMIC AND RESEARCH POSITIONS}

Women use their STEM Ph.D.s in many ways. The published degree information does not allow us to see what happens to women after receiving their degrees. One destination of many $\mathrm{Ph}$.D. recipients is a tenure-track position at an academic or research institution. Women in these positions are particularly important as role models, encouraging more junior women to pursue science degrees. Women in academic positions are also relatively easy and the personnel lists from web sites of six major oceanographic institutions, schools, and departments as given in the winter of 2004 to 2005.

\section{AGI Data 2002}

The AGI data are self-reported. The 2002 Directory of Geoscience Departments (Claudy, 2002) shows that for the geosciences overall, women are present in lower proportions, 12 percent at Ph.D.granting institutions versus 17 percent at bachelor's-degree-granting. Women are present in higher proportions at lowerranking academic positions at both types of institutions (Figure 8). Master's-degree-granting institutions show a different pattern, with a higher proportion of women associate professors and a lower proportion of women full professors than bachelor's-degree-granting institutions. The higher proportions in lower-ranking positions are not surprising because of the considerable time it takes to move from assistant to full professor, which is about fourteen years. What is surprising is that the proportions at the rank of pro- 


\section{Oceanography in Spain: Gender Issues}

BY CAMINO LIQUETE

Oceanography is a thriving profession in Spain-though it is still male-dominated. Women oceanographers currently represent 42 percent of Spanish marine researchers (Figure 1). This seemingly high percentage is not homogeneous across all work classifications. Overall, 26 percent of Spanish oceanographers are men with permanent positions, while only 11 percent of women have similar permanent positions (Figure 2). The statistics show that most of the marine scientists who are grant holders are women (23 percent, versus 18 percent for men) (Figure 2). This job contrast is even greater at Spanish universities than in research institutes where men hold far more permanent posts (Figure 3).

Gender distribution is also different among specializations. Men and women are more or less evenly balanced in marine biological-ecological and chemical groups (ratios are 53/47 percent and 52/48 percent, respectively), while male dominance is obvious among geological and physical oceanographers (62/38 percent and 66/34 percent, respectively) (Figure 4). Male geological and physical oceanographers can represent 75 percent of specific marine-science e-mail lists.

The population of Spanish undergraduate oceanography students (a fiveyear degree that comprises all of marine sciences) is about 2500 , but these num- bers decreased slightly between 1998 and 2001. Nevertheless, the percentage of women undergraduate oceanography students grew from 57 to 63 percent during the same period, exceeding the national female university students' ratio.

In conclusion, currently in Spain the majority of oceanographers are men, and men still hold the best jobs. However, the number of women in this field is increasing, and for the time being it seems that women represent most of the young marine scientists. It should be pointed out that recently some Spanish women have reached very important posts, such as the Minister for Education and Science (M.José San Segundo) and

the Director-General of the

Spanish Oceanographic Institute (M. Concepción Soto) (photo).

So, it appears that at least in Spain, women oceanographers are becoming more equal in the highest working ranks. Undoubtedly, these numbers will improve even more in the future.

Camino Liquete (cliquete@geo.ub.es) is a Ph.D. candidate, GRC Geociències Marines, Departament d'Estratigrafia, Paleontologia i Geociències Marines, Universitat de Barcelona/Facultat de Geologia Campus de Pedralbes, Barcelona, Spain.
Figure 3.

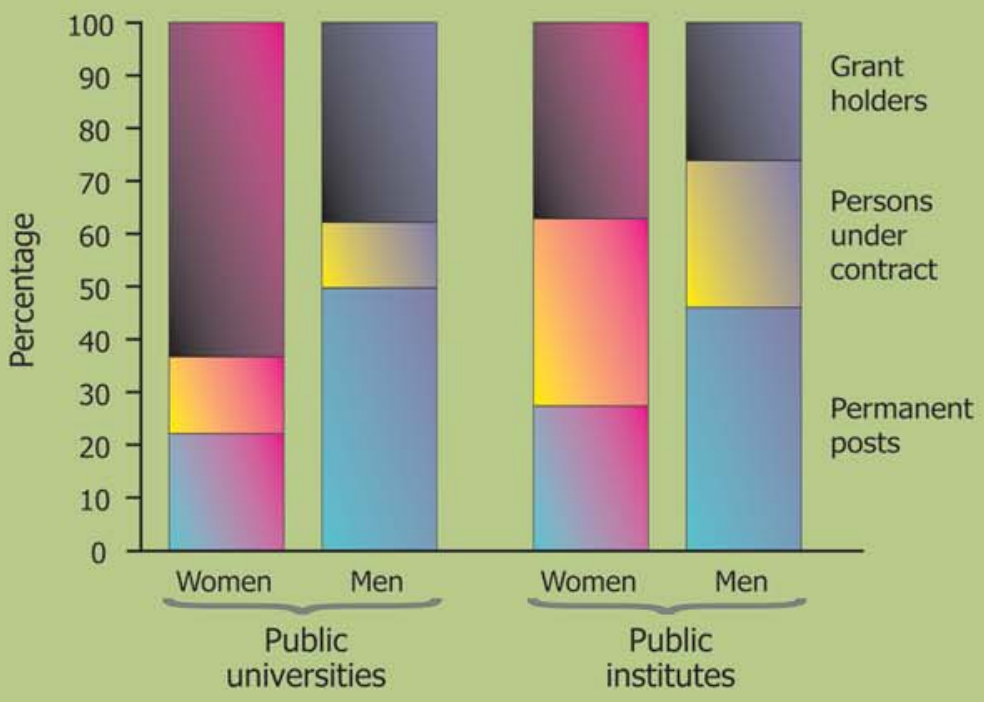

Figure 4.

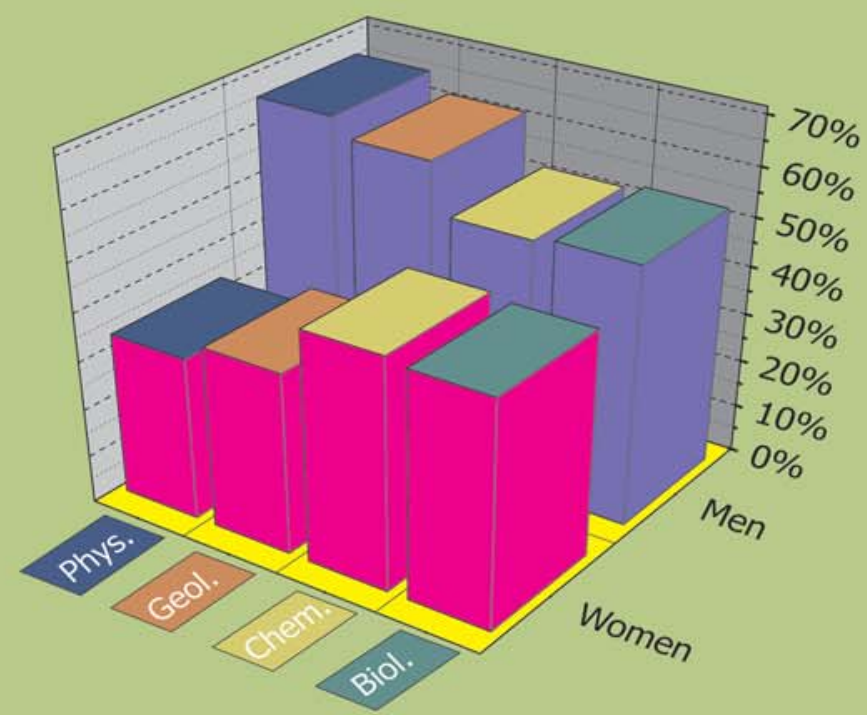




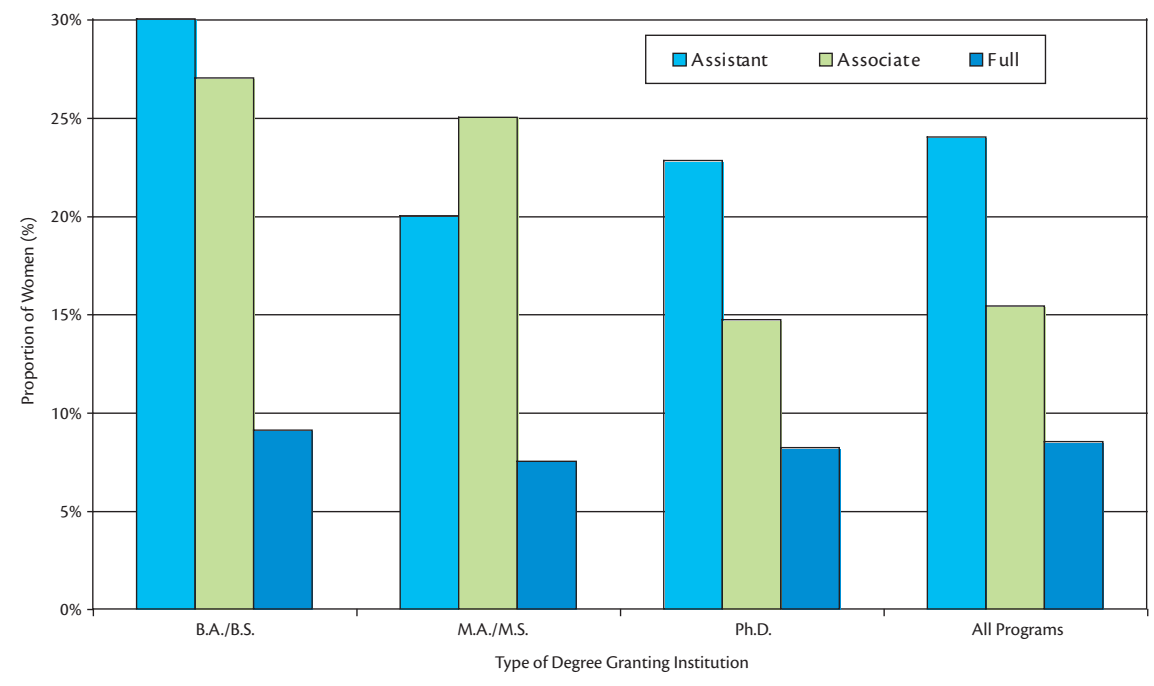

Figure 8. Proportion of women geoscience faculty in different degree-granting departments by academic rank in 2001-2002. There are 219 BA/BS departments with an average of seven faculty, $99 \mathrm{MA} / \mathrm{MS}$ departments, with an average of nine faculty, and $272 \mathrm{Ph}$.D.-granting departments with an average of 16 faculty, for a total of 590 departments with an average of 12 faculty. At all academic levels, women are more likely to be at a bachelor's (17 percent) than a Ph.D. (12 percent) granting institution. Data from Claudy (2002) and Holmes and O'Connell (2004),

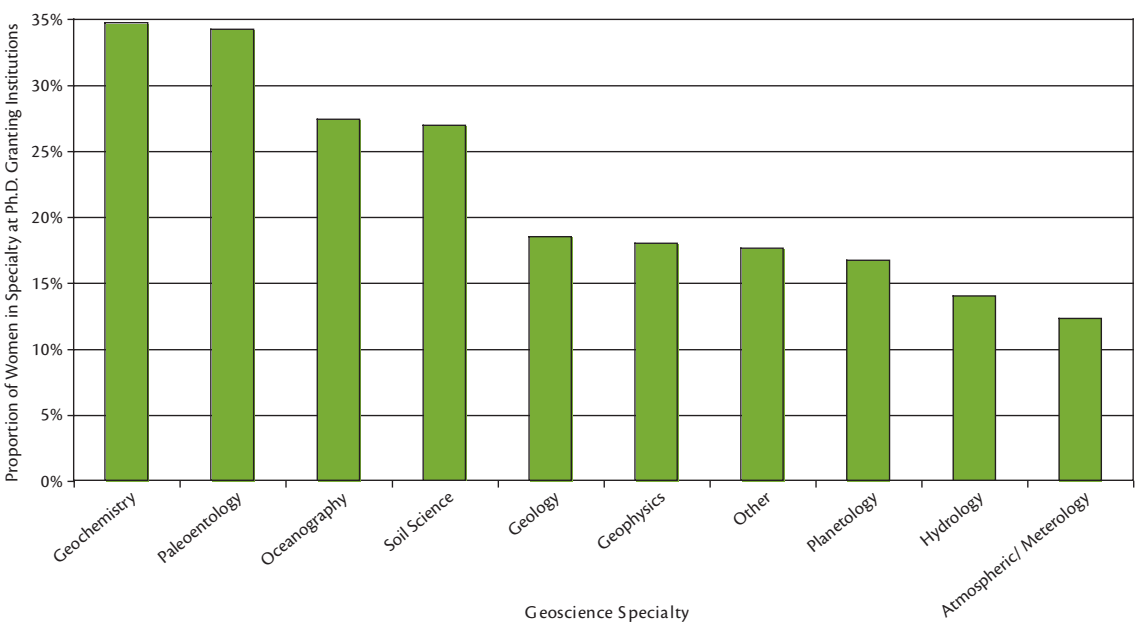

Figure 9. Proportion of women in different geoscience specialties as self reported in the 20012002 AGI Directory of Geoscience Departments. Data from Claudy (2002) and Holmes and O'Connell (2004). Oceanography is the third most popular area for women in Ph.D.-granting geoscience departments. The actual number of oceanographers is likely to be underrepresented because women in some fields, especially biological oceanography, are unlikely to be represented in these data. fessor at all types of institutions are still so low (less than ten percent).

Oceanography is primarily a graduate field, so only Ph.D.-granting institutions are included in Figure 9. Approximately 28 percent of the 581 tenured and tenure-track faculty at Ph.D.-granting institutions that list oceanography as their primary discipline are women, making it the third most popular sub-discipline listed by women geosciences faculty. With the exception of department chairs or heads, women in oceanography are better represented by two to three percent more at each faculty rank than the average for geoscience departments (Figure 10).

\section{Oceanographic Institutions}

As a second approach to assessing women's employment in academic oceanography, we examined the faculty web pages of six major oceanographic institutions, schools, and departments, including:

- College of Oceanic and Atmospheric Sciences, Oregon State University

- Graduate School of Oceanography, University of Rhode Island

- Department of Oceanography, University of Washington

- Rosenstiel School of Marine and Atmospheric Sciences, University of Miami

- Scripps Institution of Oceanography, University of California San Diego

- Woods Hole Oceanographic Institution

These schools were chosen because they represent five of the original six institutions that formed Joint Oceanographic Institutions for Deep Earth Sampling (JOIDES) and consist of private and public institutions and institutions of different sizes. The sixth original JOI 
institution, Lamont Doherty Earth Observatory, was not included because it has many non-oceanographic Earth scientists. Reviewing the six web pages allowed us to better quantify the number of women in oceanography today. Also, by reviewing the web sites directly, we were able to add the names of those who may not be listed in the AGI geoscience directory because of a different subspecialty, such as biological oceanography.

We needed a method to accommodate the different ranking criteria and different disciplines among the six institutions studied. Some institutions had different job titles (full professor vs. senior scientist) and also listed staff under several subdisciplines within oceanography. For example, Woods Hole Oceanographic Institution does not have faculty per se, but they have a scientist rank that roughly follows faculty ranking. To equalize our data, we included only scientists and departments in the four major oceanography disciplines discussed earlier (i.e., physical, chemical, biological, and geological oceanography). Schools or departments of coastal studies, engineering, and policy were not included. In addition, only faculty in tenure-track or tenure-track-equivalent job titles (e.g., associate scientist) were included. Not included in our analysis were research positions, which usually imply that a higher proportion of salary comes from research grants rather than guaranteed by the institution, and emeritus positions.

Some scientists were difficult to place in one category because their subspecialty belonged in more than one category. If no specific department was listed for a scientist (e.g., at Oregon State University), we used their research information

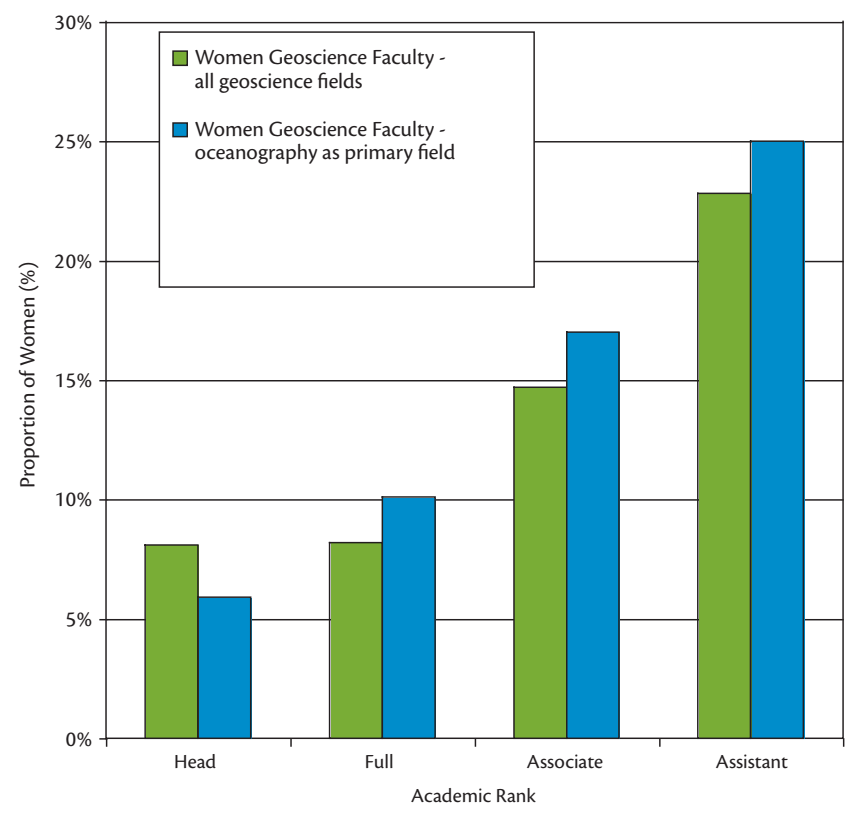

Figure 10. Proportion of women in tenure-track academic positions by rank at Ph.D. granting institutions who list oceanography as one of their subspecialities, compared with averages for Ph.D. programs in the geosciences for the academic year 2001-2002. Women in oceanography are better represented at all ranks, except department head, than the geosciences as a whole. Data from Claudy (2002) and Holmes and O'Connell (2004).

to place them into an appropriate category. For example, a scientist whose research area is defined as nutrient cycling was placed in chemical oceanography, but if organisms themselves were the research focus, the scientist was considered a biological oceanographer. A total of 411 scientists were counted, of which 353 $(83.5 \%)$ were men and 68 (16.5 percent) were women.

As was seen with the geoscience department data (Figure 8), most men (221) in the oceanography departments surveyed have reached the level of full professor (Figures 11a and 11b). In contrast, the number of women full professors is low (20 women or 9 percent), and unlike their male colleagues, the total numbers of women in all areas and ranks is surprisingly constant (Figure 11c). Because women are present in the highest numbers in the biological sciences (Figure 4), it might be expected that women would be represented in the highest proportion in biological oceanography. Although it is true that women are in higher proportions in biological oceanography at the assistant and full professor ranks, it is not true at the associate rank, where both geological and chemical oceanography have a higher proportion of women. Particularly impressive is the increase in the proportion of women in physical oceanography, from 1.6 percent at the full professor level to 35 percent at the assistant professor level. Relative to other fields, the geosciences have the highest proportion of women at the associate level (28 percent) and the lowest at the assistant professor level (15 percent). All of these proportions are based on very small numbers (Figures 11b and 11c), so if one or two women get promoted or fail to get promoted, they can have a large impact on the proportion.

All fields except geological oceanography (marine geology and geophysics) 

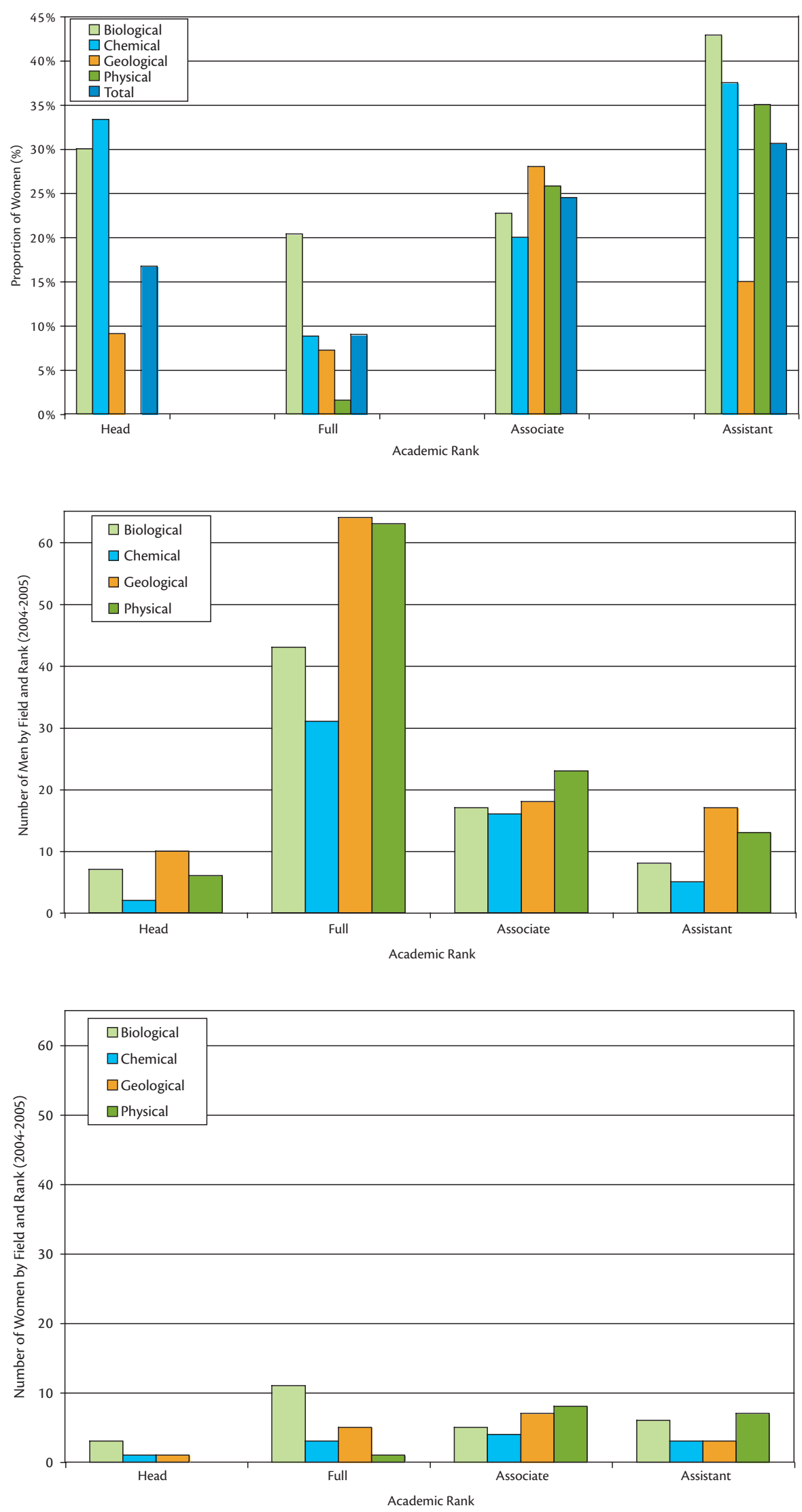

Figure 11a. Proportion of women in the four major subfields of oceanography by rank. Data based on web site faculty listings at six major oceanographic institutions, schools, and departments (see text for specific institutions included and methods). Four hundred and eleven scientists were counted.

Figure 11b. Number of men by subdiscipline and in faculty positions at six major oceanographic institutions, schools, and departments. Three hundred and forty-three men were counted.

Figure 11c. Number of women, by sub-discipline and rank at six major oceanographic institutions, schools, and departments. Sixtyeight women were counted. 
show a steady increase in the proportion of women from higher to lower rank

(Figure 11a). The proportion of women in geological oceanography is highest at the associate level.

Comparing the oceanographic institution ranking data (Figure 11a) with the AGI ranking data for women listing oceanography as a primary field (Figure 10), women are represented in higher proportions at these six oceanographic institutions on average at all ranks except full professor, where the proportion is slightly lower (by 1 percent). However, comparing women in the geoscience subfield of oceanography (Figure 10) with women selecting oceanography as a primary field in the AGI directory (Claude, 2002), women at oceanographic institutions are better represented only at the associate rank.

\section{DISCUSSION}

Although women continue to join the ranks of academic oceanographers in increasing numbers (Figure 6), there is still a considerable gap between the number of men and the number of women in the in society. As undergraduates, they select scientific careers in lower proportions, and relatively fewer women than men go on to complete a Ph.D., at least within the seven-year period we've assumed in this study. Then the proportion of women who, having completed an advanced degree, get tenure track jobs (Figure 3) is even lower. In addition, focus groups looking at women's participation in the geosciences have shown that women are more likely than men to consider leaving the field at every step of their careers, even after tenure (Holmes and O'Connell, 2004). Family considerations and problems with graduate advisors play a large role in these considerations.

One of the most important family considerations is if and when to have children. In an academic life there is no good time to have a family. Oceanography is a particularly demanding career, and sea-going work can mean weeks and even months away from family. Women who follow a fairly straight path from a bachelor's degree to a tenure-track academic job are likely to be in their mid to late 30 s when they achieve tenure (deWet

\section{Although women continue to join the ranks of}

academic oceanographers in increasing numbers, there is still a considerable gap between the number of men and the number of women in the field.

field. There are many reasons for this gap; some are addressed by Bell et al. (this issue) and Marcus (this issue). Our data for the geosciences show that along the entire academic track, women are underrepresented relative to their proportion et al., 2002). Having children when older increases the chances of miscarriage, Down's Syndrome, and infertility.

The difficulties of combining an academic career and family, especially children, are not limited to oceanography.
The problem is endemic in throughout academia. A study of all fields, completed by Mason and Goulde at the University of California and reported by Wilson (2003), found that for women pursing academic careers, those who have a baby within five years of earning a Ph.D. are nearly 30 percent less likely than childless women to get a tenure-track position. Fourteen years after receiving a Ph.D., only 56 percent of women who had babies early had earned tenure. In contrast, 77 percent of men who became fathers early had earned tenure. Only 71 percent of childless men got tenure.

\section{CONCLUSIONS}

The participation of women in academic oceanography follows that of other scientific fields. Most faculty are male full professors. Women are more likely to be found at the assistant professor rank than at full professor rank. Because it takes about 14 years to move from a Ph.D. to full professor, and once in the position, a scientist is likely to remain there for 20 to 40 years, it is understandable that women who earned such a small percentage of the Ph.D.s 20 to 40 years ago are poorly represented at this rank. What is surprising is that even with the increase of women in both absolute numbers and proportions, the number of women remains so low at the entry level assistant professor rank.

There has been much speculation about the reasons for this low number of women at the assistant professor level, including family responsibilities (Wilson, 2003; deWet et al., 2001; Holmes and O'Connell, 2004), aptitude (Healy and Rimer, 2005), and climate (Holmes et al., 2003; Holmes and O'Connell, 2004). 
There is probably no one reason for the low numbers of women in academia. But the academic system was designed when women were not a common presence in the academy and when most faculty had wives who did not work outside of the home. Today, with two-career families and women wanting to participate in both the academy and the family, the system must become more flexible to respond to these changing needs. Unfortunately, changing such an entrenched system is not easy.

The ADVANCE program at NSF (see Bell et al., this issue) is attempting to provide the structure that will allow academic institutions to make the changes gests the following strategies to survive in academia:

- Find out what is expected by both the employer and the academy as a whole to navigate the tenure track successfully

- Develop a strategic plan for each area of tenure evaluation

- Follow the plan

- Seek guidance and help early and often Women following this advice aren't guaranteed a tenured job in oceanography, but it will increase their chances of getting and retaining one; each retention increases the number of women in the academic pool. Oceanography is a challenging and fulfilling field, one

\section{Oceanography is a challenging and fulfilling field, one that}

women are pursuing in increasing numbers. We hope this

trend continues and that barriers to women's success in

oceanography and all areas of academia diminish with time.

necessary to increase the participation of women. Women themselves can prepare for their career challenges by becoming informed about the challenges and developing strategies to deal with them. Several "how to" books are available and include: Becoming Leaders: A Handbook for Women in Science Engineering, and Technology by Mary Williams and Carolyn Emerson; and To Boldly Go: A Practical Career Guide for Scientists, by Peter Fiske. Another source is a workshop report written by the authors of this article, entitled Where are the Women Geoscience Professors? This report sug- that women are pursuing in increasing numbers. We hope this trend continues and that barriers to women's success in oceanography and all areas of academia diminish with time.

\section{ACKNOWLEDGEMENTS}

We would like to thank the American Geological Institute for providing the academic geoscience data, Beck Straley for compiling the DSDP and ODP data, and Tom Davies for providing additional ODP data. This work was funded by an NSF ADVANCE Grant (123669) to the co-authors. שs

\section{REFERENCES}

Claudy, N., ed. 1997. Directory of Geoscience Departments, 2001-2002. American Geological Institute, Alexandria, VA.

Claudy, N., ed. 2001. Directory of Geoscience Departments, 2001-2002. American Geological Institute, Alexandria, VA.

Claudy, N., ed. 2002. Directory of Geoscience Departments, 2001-2002. American Geological Institute, Alexandria, VA.

de Wet, C., G.M. Ashley, S. Liuti, and D.P. Kegel. 2002. Biological clocks and tenure timetables: restructuring the academic timeline." GSA Today (suppl.):1-7. [Online] Available at: http: www.geosociety.org/pubs/gsatoday/0211clocks/ 0211clocks.htm.

Fiske, P.S. 1996. To Boldly Go: A Practical Career Guide for Scientists. American Geophysical Union, Washington, DC, 188 pp.

Healy, P.D. and S. Rimer. 2005. Furor Lingers as Harvard Chief Gives Details of Talk on Women, New York Times, February 18, 2005. [Online] Available at: http://www.nytimes. com/2005/02/18/education/18harvard.html?ex= 1109394000\&en=b998704876947558\&ei $=5070$.

Holmes, M.A. and S. O'Connell. 2004. Where are the Women Geoscience Professors, Workshop Report, 40 pp. [Online] Available at www.awg.org.

Holmes, M.A., S. O'Connell, C. Frey, and L. Ongley. 2003. Academic Specialties Shifting: Hiring of Women Geoscientists Stagnating. Eos, Transactions American Geophysical Union 84:457, 460-461.

National Science Foundation (NSF). 2003. Science and Engineering Doctorate Awards: 2003, NSF 05-300. National Science Foundation, Division of Science Resources Statistics, Arlington, VA. [Online] Available at: http://www.nsf.gov/sbe/ srs/nsf05300/start.htm.

National Science Foundation. 2004. Science and Engineering Degrees: 1966-2001, NSF 04-311. National Science Foundation, Division of Science Resources Statistics, Arlington, VA. [Online] Available at: http://www.nsf.gov/sbe/srs/ nsf04311/htmstart.htm.

Williams, F.M. and C.J. Emerson. 2002. Becoming Leaders: A Handbook for Women in Science Engineering, and Technology. NSER/Petro-Canada Chair for Women in Science and Engineering. Memorial University, St. John's, NL, Canada, 142 pp. [Online] Available at: http://www3. nf.sympatico.ca/carolyn.emerson/orderform. htm.

Wilson, R. 2003. How Babies Alter Careers for Academics. The Chronicle of Higher Education 50(15):A1. 